\title{
RATIONAL EXUBERANCE AT THE MALL: ADDICTION TO CARRYING A CREDIT CARD BALANCE*
}

\author{
Kaili Shen \\ \& \\ David E. Giles \\ Department of Economics, University of Victoria \\ Victoria, B.C., Canada V8W $2 Y 2$
}

June, 2005

\begin{abstract}
We test the Becker-Murphy model of rational addiction with New Zealand credit card debt data. Our results clearly favour the rational addiction model over the myopic, backward-looking model. The estimated short-run and long-run price elasticities are -0.58 and -2.32 respectively, and the estimated rate of time-preference is $6.7 \%$ per quarter.
\end{abstract}

Keywords: $\quad$ Rational addiction, credit card debt

JEL Classifications: D12; D14; D91; I12

\section{Author Contact:}

David Giles, Dept. of Economics, University of Victoria, P.O. Box 1700, STN CSC, Victoria, B.C., Canada V8W 2Y2; e-mail: dgiles@uvic.ca; FAX: (250) 721-6214 


\section{Introduction}

There are two competing approaches to modeling the demand for addictive substances. One is the myopic model of Gorman (1967), Pollak (1970), Hammond (1976), and others. The other is the rational addiction model introduced by Becker and Murphy (1988). The latter approach has dominated the empirical modeling of addictive goods since the end of the 1980's. The consumer in the myopic model simply makes backward-looking decisions, which recognize the dependence of current consumption on past consumptions, but which ignore the impacts of current and past choices on future outcomes when making current consumption choices. In contrast, in the rational addiction model the consumers are rational and farsighted, and take into account the consequences of past and current consumptions on future outcomes when making current decisions.

Becker and Murphy (1988) proposed a theoretical model in which forward-looking, utilitymaximizing consumers may become addicted to the consumption of a good. Consumers are rational in the sense that they can anticipate the expected future consequences of their current actions. The rational consumer may still choose to be addicted if he or she evaluates the benefits of the addiction to be greater than its full cost, discounted over time. Addiction requires interaction between a person and a good. People can be addicted not only to harmful goods like cigarettes, alcohol, and illegal drugs, but also to activities that may seem to be physically harmless, such as sports participation, shopping, listening to music, watching television, working, etc.

In this paper we test the rational addiction model in a new context - carrying debt on credit cards. For many people, carrying credit card debt is a fact of modern life. However, is the consumption of this form of credit rational, or merely habitual? Specifically, we test the model against New Zealand quarterly time-series data on credit advances outstanding, from June 1992 to June 2004. Section 2 outlines the theoretical model and deals with some specification, estimation and testing considerations. In section 3 we provide a brief review of some of the empirical tests of the rational addiction hypothesis in the literature. Our own empirical analysis is introduced in Section 4, and our results are presented in Section 5. The last section provides some concluding remarks. 


\section{Modeling and Testing Rational Addiction}

The rational addiction model assumes that the individual consumer has a utility function in period $t$ :

$$
U_{t}=U\left(y_{t}, c_{t}, a_{t}, e_{t}\right),
$$

where $c_{t}$ is consumption of the addictive good, $y_{t}$ is consumption of other goods, $a_{t}$ is the accumulated stock of the addictive good, and $e_{t}$ reflects the impact of unmeasured life cycle variables on utility. The stock of the addictive good depends on past consumption:

$$
a_{t}=(1-\delta) c_{t-1} .
$$

It is assumed that consumers are infinitely lived and are maximizing lifetime utility subject to a lifetime budget constraint:

$$
\begin{aligned}
& \operatorname{Max} U(0)=\sum_{t=1}^{\infty} \beta^{t-1} U\left[y_{t}, c_{t},(1-\delta) c_{t-1}, e_{t}\right] \\
& \text { Subject to } \sum_{t=1}^{\infty} \beta^{t-1}\left(y_{t}+p_{t} c_{t}\right)=w_{0},
\end{aligned}
$$

where $\beta=1 /(1+r)$ is the discount factor, and $r$ is the rate of interest which is assumed to be equal to the intertemporal rate of time preference. $p_{t}$ is the price of the addictive good, and $w_{0}$ is the present value of lifetime wealth. Optimizing a quadratic version of the utility function yields the linear demand function:

$$
c_{t}=\theta_{0}+\theta_{1} c_{t-1}+\theta_{2} c_{t+1}+\theta_{3} p_{t}+\theta_{4} e_{t}+\theta_{5} e_{t+1}
$$

where $\theta_{2}=\beta \theta_{1}$ and $r=\left[\left(\theta_{1} / \theta_{2}\right)-1\right]$. So, current consumption of an addicted good is a function of past and future consumption, price, and the unobservable variables $e_{t}$ and $e_{t+1}$, representing the impact of unmeasured life cycle variables.

The myopic model explains consumption only in terms of current and past factors:

$$
c_{t}=\theta_{0}+\theta_{1} c_{t-1}+\theta_{2} p_{t}+\varepsilon_{t} \text {. }
$$

This model, which implies a zero discount rate and an infinite rate of time preference, is nested within the rational addiction model, so a test of the significance of the coefficient of $c_{t+l}$ in (1) can be used to discriminate between the two models. Some studies also control for an income effect in the rational addiction model. Examples include Cameron (1999), Lalla et al. (2003) and Tiezzi (2003), and we also augment our model in this way. 
Solving the second-order difference equation (1) leads to the characteristics roots:

$$
\lambda_{1,2}=\left[1 \mp\left(1-4 \theta_{1} \theta_{2}\right)^{1 / 2}\right] / 2 \theta_{1},
$$

where $\lambda_{1}$ and the inverse of $\lambda_{2}$ measure the response of current consumption caused by a shock to future and past consumption respectively. As long the utility function is concave in $c_{t}$ and $c_{t-1}$, the signs of these roots will positive if addictive behavior is present (Sisto and Zanola, 2004). Then, solving equation (1) for $c_{t}$, we can derive the short-run and long-run price elasticities as:

$$
\begin{aligned}
& \eta_{s}=\frac{\partial c_{t}}{\partial p_{t}} \frac{p}{c}=\frac{\theta_{3}}{\theta_{1}\left(1-\lambda_{1}\right) \lambda_{2}} \frac{p}{c} \\
& \eta_{l}=\frac{\partial c_{\infty}}{\partial p} \frac{p}{c}=\frac{\theta_{3}}{\theta_{1}\left(1-\lambda_{1}\right)\left(\lambda_{2}-1\right)} \frac{p}{c}
\end{aligned}
$$

We will accept the rational addiction hypothesis when the coefficients of both future and past consumption are positive and significant, and the implied discount rate is also positive. A positive and significant coefficient on the lag of consumption indicates that the consumers are addictive to the good they consume, while a positive and significant coefficient for future consumption indicates that consumers are rational and forward-looking. As we expect $r>0$, we should also expect $\theta_{1}>\theta_{2}$. The price coefficient, $\theta_{3}$, is expected to be negative and significant. In addition, from equations (2) we see that for the long-run price elasticity to exceed the short-run elasticity we require $\lambda_{2}>1$, which is ensured if $\theta_{1}>0$ and $\left(\theta_{1}+\theta_{2}\right)<1$.

\section{Some Previous Studies}

There have been numerous empirical applications of the rational addiction model, and a few representative ones are discussed briefly here. Studies involving the consumption of alcohol include those of Grossman et al. (1998), Bentzen et al. (1999), Baltagi and Griffin (2002) and Lalla et al. (2003). Bentzen et al. used aggregate data for the consumption of spirits and wine in Sweden, and Lalla et al.(2003) used Norwegian data based on diaries for 209 households over the period 1997 to 1999. Grossman et al. used surveys of high school seniors over the period 1976 to 1985 to test the rational addiction hypothesis for liquor consumption; and Baltagi and Griffin (2002) based their analysis on a panel for 42 U.S. states over the period 1959 to1994. Although all of these studies found support for the rational addiction hypothesis, the results of Grossman et al. (1998) and Baltagi and Griffin (2002) are not fully consistent with rational addiction, as their 
estimates of the discount factor were negative. These implausible interest rates may be attributable to the type of data used.

In the case of tobacco products, Becker et al. (1994) used annual per capita cigarette sales data for US states over the period 1955 to 1985, while Chaloupka (1991) used micro data on cigarette consumption from national health and nutrition examination surveys. Both studies rejected the myopic addictive model and found support for the rational addiction model. More recent studies include those of Bask (2000), whose study allowed for both legal and illegal tobacco, Baltagi and Griffin (2001), and Tiezzi (2003). The latter author estimated the demand for tobacco and related products in Italy using both time-series data and panel data for twenty Italian regions. Strong support for the rational addiction hypothesis was found with the former data, and modest support in the case of the panel data. Again, some of the authors (e.g., Bask) obtained implausible negative estimates for the discount rate. According to Baltagi and Griffin (2001, p.454): “... aggregate panel data do not seem likely to provide sharp estimates of the discount rate", but Laux (2000, p.428) claims that this result signals the failure of the rationality hypothesis. In our own study we take the latter stance.

Other studies that focus on highly addictive goods include those of Grossman et al. (1999), who modeled the demand for cocaine and obtained a long-run price elasticity estimate of -1.35 . Bretteville-Jensen and Biørn (2003) used panel data for heroin addicts in Oslo, and found more support for the myopic model than for the rational addiction model. At a somewhat different level, Olekalns and Bardsley (1996) tested the model against data for the consumption of coffee, and obtained positive results.

In addition, interest in the rational addiction model has expanded to some goods where no biological or pharmaceutical dependency arises. For example, Cameron (1999) applied this model to the demand for cinema, using pooled cross-section and time-series data. The results were not particularly supportive of the rational addiction model. In contrast, Sisto and Zanola (2004) considered the demand for cinema by using pooled cross-section and time-series data for thirteen European countries over the period 1989 to 2002, and their results strongly favoured the rational addiction hypothesis. Dewenter (2003) also found support for the Becker and Murphy model in the context of print media consumption, by using quarterly data for magazine circulation in a panel framework. 
In summary, the empirical evidence regarding the rational addiction model is very mixed. The results appear to be quite sensitive to the type of data that are used, as well as the product under consideration.

\section{Data and Model Specification}

In this study we apply the rational addiction model to quarterly New Zealand credit card advances outstanding data, from 1992Q2 to 2004Q2. ${ }^{1}$ The empirical model estimated is:

$$
c_{t}=\theta_{0}+\theta_{1} c_{t-1}+\theta_{2} c_{t+1}+\theta_{3} p_{t}+\theta_{4} p d i_{t}+\varepsilon_{t}
$$

The dependent variable is per capita (18 years and older) credit card advances outstanding measured in New Zealand dollars, and deflated by the credit card interest rate. The price variable, $p_{t}$, is the average standard credit card interest rate, divided by the CPI (excluding credit services); and $p d i_{t}$ is per capita (18 years and older) real disposable income. Quarterly seasonal dummy variables are also included in the model.

Before estimating our model we tested if the data are stationary. ${ }^{2}$ We tested for unit roots at the zero frequency using the augmented Dickey-Fuller (ADF) test, and at the seasonal frequencies via the testing procedure proposed by Hylleberg et al. (1990) - hereafter HEGY. The $\pi_{1}$ and $\pi_{2}$ tests are for unit roots at the zero and $\pi$ frequencies; and $F_{34}, F_{234}$, and $F_{1234}$ denote tests for unit roots at the $(\pi / 2)$ and $(3 \pi / 2)$ frequencies, all seasonal frequencies, and all frequencies respectively. The results are shown in Table 1, and they indicate that each series has a unit root at the zero frequency, but not at the seasonal frequencies. Accordingly, we tested for cointegration at the zero frequency, using Johansen's (1991) tests. The lag length for the associated VAR models was chosen to be five, on the basis of AIC, SC and FPE criteria. As the series exhibit linear trends, we follow the suggestion of Franses (2001) and include a drift and trend in the cointegrating equation, and a drift but no trend in the VAR models when applying Johansen's procedure. This corresponds to 'case 4' in the EViews (2004) econometrics package. The cointegration testing results also appear in Table 1. Both the trace and maximum eigenvalue tests suggest that there are three cointegrating relationships, and this supports estimating our model using the levels of the data, rather than undertaking any filtering or estimating an error-correction model. ${ }^{3}$ 


\section{Empirical Results}

Given the presence of the lagged dependent variable, OLS estimation of equation (1) will lead to biased estimates of the parameters. Moreover, the derivation of the model suggests that the unobservable are likely to follow an MA(1) process, so the parameter estimates and the standard errors will be inconsistent, and the usual hypothesis tests will also be distorted. We can use Maximum Likelihood estimation (MLE) to take account of the serial correlation in the errors, but care must also be taken with the possibly endogenous future and past consumption regressors. Instrumental Variables (IV) estimation is a natural choice, and Becker et al. (1994) suggest using $p_{t-1}$ and $p_{t+l}$ as instruments for $c_{t-1}$ and $c_{t+1}$.

Our estimation results are shown in Table 2, where DQ1 to DQ3 are quarterly seasonal dummy variables. As can be seen in the first two columns of Table 2, MLE produces coefficient estimates that are significant and of the anticipated signs. The relative magnitudes of the coefficients on the lead and lag of consumption ensure a positive and plausible estimate for the rate of time preference. The significant coefficients for $c_{t-1}$ are consistent with both the myopic and rational addiction models. However, the significant coefficients for $c_{t+1}$, and the positive characteristic roots, clearly favour the latter model. The fact that one root is less than unity, and the other exceeds unity, implies that the estimated model is dynamically stable.

The $\mathrm{Wu}(1973)$ test statistic is $2.573(p=27.6 \%)$, so we cannot reject the hypothesis that the regressors in (3) are asymptotically uncorrelated with the errors. ${ }^{4}$ However, by way of comparison we have included IV estimation results in Table 2. If an allowance is made for a moving average process in the errors in this case, the relative magnitudes of coefficients on $c_{t-1}$ and $c_{t+1}$ imply negative estimates of the rate of time preference. As can be seen in Table 2, regardless of the choice of instruments, IV estimation yields insignificant income and price effects, which is also unsatisfactory.

Based on the preferred results in the first column of Table 2, our estimate of the rate of time preference is $6.7 \%$ per quarter, which compares favourably with Tiezzi's (2003) estimate of $24 \%$ p.a. in his study of Italian smokers. In contrast, Sisto and Zanola (2004) obtained a rate of 58\% p.a. for cinema addiction. Our estimated short-run price elasticity of -0.58 is similar to those found in studies of other addictive goods. For example, Dewenter (2003) obtained an estimate of -0.47 in the case of addiction to news, and Sisto and Zanola reported an estimate of -0.55 for 
cinema addiction. The corresponding long-run price elasticity estimates were -1.97 and -2.12 respectively, compared with our own estimate of -2.32 . Not surprisingly, smaller long-run price elasticities are typically found in studies relating to tobacco and alcohol. For example, Bask (2000) obtains an estimate of -1.02 for cigarettes, and Baltagi and Griffin (2002) report a value of -1.24 for alcohol.

\section{Conclusions}

This paper tests the rational addiction model for a good not previously considered - credit card debt carried over from one month to the next. We find strong support for this model in the context of New Zealand time-series data, and clearly reject the myopic, backward-looking model. Our preferred results incorporate a significant income effect and imply plausible price elasticity estimates. The model is dynamically stable, and the estimated rate of time preference is positive and of a credible magnitude. 
Table 1: Unit Root and Cointegration Test Results

\begin{tabular}{|c|c|c|c|c|c|c|c|c|}
\hline \multicolumn{9}{|c|}{ (a) ADF Tests ${ }^{*}$} \\
\hline & $\mathbf{k}$ & \multicolumn{2}{|c|}{ No Drift or Trend } & \multicolumn{2}{|l|}{ Drift } & \multicolumn{3}{|c|}{ Drift \&Trend } \\
\hline $\mathbf{c}_{\mathbf{t}}$ & 4 & 1.243 & $(0.943)$ & 0.039 & $(0.957)$ & -2.089 & $(0.538)$ & \\
\hline $\mathbf{p}_{\mathrm{t}}$ & 0 & -1.951 & $(0.050)$ & -0.598 & $(0.861)$ & -1.532 & $(0.804)$ & \\
\hline \multirow[t]{3}{*}{$\operatorname{pdi}_{t}$} & 0 & 3.745 & $(0.999)$ & 0.111 & $(0.963)$ & -1.824 & $(0.677)$ & \\
\hline & \multicolumn{8}{|c|}{ (b) HEGY Tests ${ }^{* *}$} \\
\hline & $\mathbf{k}$ & $\pi_{1}$ & $\pi_{2}$ & & $\mathbf{F}_{34}$ & $\mathbf{F}_{234}$ & & $\mathbf{F}_{1234}$ \\
\hline$c_{t}$ & 0 & $-1.791^{+}$ & -3.60 & & 20.727 & 32.397 & & 27.646 \\
\hline $\mathbf{p}_{\mathrm{t}}$ & 1 & $-1.512^{+}$ & -3.63 & & 10.296 & 12.556 & & 13.107 \\
\hline pdi $_{t}$ & 1 & $-0.964^{+}$ & -3.610 & & 11.051 & 11.384 & & 9.499 \\
\hline
\end{tabular}

(c) Johansen Tests ${ }^{* * *}$

Hypothesized

No. of CE's
Trace

Statistic (p-value)
Max. Eigenvalue

Statistic (p-value)

$\begin{array}{lccccc}\text { None } & 0.489 & 69.261 & (0.000) & 28.855 & (0.019) \\ \text { At most 1 } & 0.411 & 40.407 & (0.000) & 22.721 & (0.016) \\ \text { At most 2 } & 0.337 & 17.686 & (0.001) & 17.686 & (0.006)\end{array}$

* p-values, based on MacKinnon's (1996) results, appear in parentheses. The augmentation levels, $k$, were chosen using the Schwartz criterion.

** The HEGY regressions include an intercept, trend and seasonal dummy variables. The augmentation level, $k$, was chosen using the Schwartz criterion. Critical values for these tests are provided by Hylleberg et al. (1990) and Ghysels et al. (1994).

$+\quad$ Cannot reject a unit root at the zero frequency at the $10 \%$ significance level.

*** 'CE' denotes 'Cointegrating Equation'. The p-values are based on the results of MacKinnon et al. (1999). 
Table 2: $\quad$ Estimation Results for the Rational Addiction Model ${ }^{*}$

\begin{tabular}{|c|c|c|c|c|}
\hline Variable & \multicolumn{2}{|c|}{ MLE } & \multicolumn{2}{|c|}{$\mathbf{I V}^{* *}$} \\
\hline \multirow[t]{2}{*}{$c_{t-1}$} & 0.4915 & 0.4880 & 0.5129 & 0.5164 \\
\hline & $(20.420)$ & (3.933) & $(3.238)$ & (5.299) \\
\hline \multirow[t]{2}{*}{$\mathbf{c}_{\mathrm{t}+1}$} & 0.4606 & 0.4525 & 0.4633 & 0.4674 \\
\hline & $(29.288)$ & $(4.246)$ & (2.849) & (4.746) \\
\hline \multirow[t]{2}{*}{$p_{t}$} & -244.4418 & -379.8949 & -110.0087 & -72.6228 \\
\hline & $(-3.479)$ & $(-1.753)$ & $(-0.411)$ & $(-0.558)$ \\
\hline \multirow[t]{2}{*}{ pdi $_{t}$} & 0.0012 & 0.0011 & 0.0006 & 0.0004 \\
\hline & $(2.673)$ & $(0.823)$ & $(0.411)$ & $(0.605)$ \\
\hline \multirow[t]{2}{*}{ Const. } & 1.5719 & 5.5023 & 1.8196 & 2.0391 \\
\hline & (1.169) & (1.014) & $(0.329)$ & (1.065) \\
\hline \multirow[t]{2}{*}{ DQ1 } & -3.5854 & -3.4887 & -3.5961 & -3.5562 \\
\hline & $(-6.102)$ & $(-6.699)$ & $(-5.677)$ & $(-5.229)$ \\
\hline \multirow[t]{2}{*}{ DQ2 } & -2.5864 & -2.653 & -2.7115 & -2.6744 \\
\hline & $(-9.174)$ & $(-7.174)$ & $(-7.429)$ & $(-7.288)$ \\
\hline \multirow[t]{2}{*}{ DQ3 } & -3.7704 & -3.6110 & -3.6832 & -3.5683 \\
\hline & $(-7.749)$ & $(-8.206)$ & $(-6.892)$ & $(-6.607)$ \\
\hline \multirow[t]{2}{*}{ MA(1) } & -0.9975 & & & \\
\hline & $(-7.970)$ & & & \\
\hline $\bar{R}^{2}$ & 0.9987 & 0.9971 & 0.9970 & 0.9964 \\
\hline$r$ & 0.0671 & 0.0786 & 0.1071 & 0.1048 \\
\hline$\lambda_{1}$ & 0.7048 & 0.6745 & 0.7580 & 0.7884 \\
\hline$\lambda_{2}$ & 1.3296 & 1.3746 & 1.1917 & 1.1481 \\
\hline$\eta_{s}$ & -0.5752 & -0.7899 & -0.3377 & -0.2629 \\
\hline$\eta_{l}$ & -2.3203 & -2.8989 & -2.0992 & -2.0384 \\
\hline
\end{tabular}

* $\quad$ Figures in parentheses are 't-statistics', based on the Newey-West consistent covariance matrix estimator.

Elasticities are estimated at the sample mean.

** (a): instruments are constant, seasonal dummies, $c_{t-1}, p_{t-1}, p d i_{t-1}, p_{t+1}$.

(b): instruments are constant, seasonal dummies, $c_{t-1}, p_{t-1}, p d i_{t-1}, p_{t+1}, p_{t+2}, p_{t+3}$. 


\section{References}

Baltagi, H. B. and J. M. Griffin (2001), The econometrics of rational addictions: the case of cigarettes, Journal of Business and Economic Statistics, 19, 449-454.

Baltagi, H. B. and J. M. Griffin (2002), Rational addiction to alcohol: panel data analysis of liquor consumption, Health Economics, 11, 485-491.

Bask, M. (2000), Rational addiction and smoking when there are legal and illegal cigarettes, Umeå Economic Studies No 543, Department of Economics, Umeå University.

Becker, G. S. and K. M. Murphy (1988), A theory of rational addiction, Journal of Political Economy, 96, 675-700.

Becker, G. S., M. Grossman and K. M. Murphy (1994), An empirical analysis of cigarette addiction, American Economic Review, 84, 396-418.

Bentzen, J., T. Eriksson and V. Smith, (1999), Rational addiction and alcohol consumption: evidence from the Nordic countries, Journal of Consumer Policy, 22, 257-279.

Bretteville-Jensen, A. L. and E. Biørn, (2003), Heroin consumption, prices and addiction: evidence from self-reported panel data, Scandinavian Journal of Economics, 105, 661-679.

Cameron, S. (1999), Rational addiction and the demand for cinema, Applied Economics Letters, 6, 617-620.

Chaloupka, F. J. (1991), Rational addiction behavior and cigarette smoking, Journal of Political Economy, 99, 722-742.

Dewenter, R. (2003), Rational addiction to news?, Economics Discussion Paper No. 2, University of the Federal Armed Forces Hamburg.

EViews (2004), EViews 5 User's Guide, Quantitative Micro Software, Irvine CA.

Franses, P. H. (2001), How to deal with intercept and trend in practical cointegration analysis?, Applied Economics, 33, 577-579.

Ghysels, E., H. S. Lee and J. Noh (1994), Testing for unit roots in seasonal time series - some theoretical extensions and a Monte Carlo investigation, Journal of Econometrics, 62, 415442.

Gorman, W. M. (1967), Taste, habits and choices, International Economic Review, 8, 218-222.

Grossman, M., F. J. Chaloupka and C. C. Brown (1999), The demand for cocaine by young adults: a rational addiction approach, NBER Working Paper No 5713.

Grossman, M., F. J. Chaloupka and I. Sirtalan (1998), An empirical analysis of alcohol addiction: results from monitoring the future panels, Economic Enquiry, 36, 39-48. 
Hammond, P. J. (1976), Changing tastes and coherent dynamic choice, Review of Economic Studies, 43, 159-173.

Hylleberg, S., R. F. Engle, C. W. J. Granger and B. S. Yoo (1990), Seasonal integration and cointegration, Journal of Econometrics, 44, 215-238.

Johansen, S. (1991), Estimation and hypothesis testing of cointegration vectors in Gaussian vector autoregressive models, Econometrica, 59, 1551-1580.

Lalla, R., K. Rickersten and P. H. Vale (2003), Rational addiction for alcohol: a panel study of Norwegian beer drinkers, Seminar Paper, Department of Economics \& Resource Management, Norwegian University of Life Sciences.

Laux, F. L. (2000), Addictions as a market failure: using rational addiction results to justify tobacco regulation, Journal of Health Economics, 19, 421-437.

MacKinnon, J. G. (1996), Numerical distribution functions for unit-root and cointegration tests, Journal of Applied Econometrics, 11, 601-618.

MacKinnon, J. G., A. A. Haug and L. Michelis (1999), Numerical distribution functions of likelihood ratio tests for cointegration, Journal of Applied Econometrics, 14, 563-577.

Olekalns, N. and P. Bardsley (1996), Rational addiction to caffeine: an analysis of coffee consumption, Journal of Political Economy, 104, 1100-1104.

Pollak, R. A (1970), Habit formation and dynamic demand functions, Journal of Political Economy, 78, 745-63.

Sisto, A., and R. Zanola (2004), Rational addiction to cinema? A dynamic panel analysis of European countries, Working Paper 38, Department of Public Policy and Public ChoicesPOLIS, Università del Piemonte Orientale.

Tiezzi, S. (2003), Addiction and smoking behavior in Italy, Working paper series No. 412, Department of Economics, University of Siena.

$\mathrm{Wu}$, D. (1973), Alternative tests of independence between stochastic regressors and disturbances, Econometrica, 41, 733-750. 


\section{Footnotes}

* We are grateful to Elisabeth Gugl and Carl Mosk for their helpful comments, and to Weshah Razzak for his assistance with data acquisition.

1. The data are collected and calculated from the Reserve Bank of New Zealand's Money, Credit and Financial Statistics, and from Statistics New Zealand.

2. None of the series exhibit structural breaks, and this simplifies the unit root and cointegration testing.

3. If the lag length in the VAR models is shortened to four, the Johansen tests suggest there are two cointegrating relationships. Some experimentation with error-correction specifications yielded implausible results with regard to the signs of the estimated coefficients and the implied rate of time preference.

4. This test was based using $p_{t-1}$ and $p_{t+1}$ as instruments for $c_{t-1}$ and $c_{t+1}$, it allowed for the MA error process, and the Newey-West covariance matrix estimator was used. The test statistic is asymptotically chi-square with two degrees of freedom. 